\title{
LA REFORMA MONETARIA DEL TRIENIO LIBERAL EN ESPAÑA, 1820-1823: MODERNIZACIÓN Y LÍMITES*
}

\author{
Enrique Prieto Tejeiro y Dionisio de Haro Romero \\ Universidad Rey Juan Carlos, Madrid, España, \\ $<$ enrique.prieto@urjc.es>; <dionisio.deharo@urjc.es>
}

Resumen. Este trabajo pretende profundizar en el papel desempeñado por el trienio liberal en el proceso del tránsito del sistema monetario tradicional al moderno. Las fuentes primarias en las que se basa el estudio de la política monetaria de este periodo son, además de otras, las actas de la comisión parlamentaria que durante el trienio liberal aborda un proyecto de reforma del sistema monetario español heredado del antiguo régimen, y cuyos resultados se verán limitados por tres factores. En primer lugar, por la persistencia de fundamentos monetarios tradicionales; en segundo, por las dificultades para relacionar esta reforma con los debates monetarios que se están dando en los países más avanzados, especialmente Inglaterra y, en tercer lugar, por la brevedad del periodo y la restitución de la vieja política monetaria con la tarifa de Tolosa en 1823.

Palabras clave: historia monetaria, España, política monetaria, crecimiento económico, transición monetaria, trienio liberal.

Abstract. This paper aims to deepen the role played by the liberal triennial in the process of transition from traditional to modern monetary. The main sources, which the study of the monetary policy in this period is based on, in addition to other, are the acts of the parliamentary committee that during the liberal triennial deals with a draft of a reform of the monetary system inherited from the ancient regime, which results will be constrained by three factors. First, by the persistence of traditional monetary fundamentals, secondly, by difficulties in linking this monetary reform with the discussions that were taking place in the more developed countries, particularly in England, and, thirdly, the short duration of the period in which takes place and the restoration of the old monetary policy with the tariff of Tolosa in 1823.

* Este texto es el resultado de las investigaciones realizadas en el último lustro por los profesores Enrique Prieto Tejeiro y Dionisio de Haro, especializadas en la historia monetaria de la España contemporánea y desarrolladas en el Departamento de Historia e Instituciones Económicas de la Universidad Rey Juan Carlos. Agradecemos igualmente las opiniones y sugerencias emitidas por los evaluadores anónimos de la revista.

Am. Lat. Hist. Econ., año 19, núm. 2 (38), mayo-agosto, 2012, pp. 131-161 
Key words: monetary history, Spain, monetary policy, economic growth, transition monetary, liberal triennial.

Fecha de recepción: diciembre de 2010. Fecha de aceptación: abril de 2011

\section{INTRODUCCIÓN}

$\mathrm{E}$ n el origen de esta investigación está la intención de responder a interrogantes que aparecen en algunos de los estudios acerca de la política monetaria española durante la primera mitad del siglo XIX: ¿cuáles son las bases y la lógica económica sobre las que se sustentan el sistema y la política monetaria tradicional?, ¿cómo logra el sistema evitar su colapso tras la pérdida de los caudales americanos?, y ¿qué objetivos perseguía y que logros alcanzó la primera reforma monetaria liberal del siglo XIX? Asimismo, pretendemos contribuir al debate en torno a la desarticulación del sistema monetario imperial, ${ }^{1}$ la consiguiente fragmentación monetaria y la evaluación de las experiencias monetarias nacionales tras los procesos de independencia en América Latina. ${ }^{2}$ En este caso, desde la perspectiva peninsular, considerando la iniciativa del trienio liberal como parte de un complejo y compartido proceso de desintegración imperial y necesaria reestructuración nacional con el objeto de dar respuesta a un contexto monetario internacional de nueva base.

La respuesta a estas y otras preguntas relativas a la política monetaria española de este periodo se puede obtener a partir del estudio de las posiciones que se mantienen en los debates monetarios con motivo de los proyectos reformistas, y en el propio estudio de la historia monetaria ${ }^{3} \mathrm{y}$ las dificultades con las que se enfrenta el proceso de transformación del sistema monetario español durante el periodo de crisis final del antiguo régimen.

${ }^{1}$ Son numerosos los historiadores que participan de la opinión arraigada en los antibullionistas del siglo XVII de que el oro nos hizo pobres. Por ejemplo, Bennassar, España, 1983, y Kamen, Siglo, 1971, sostienen la tesis de que los metales preciosos encierran la clave de la decadencia española. Por otra parte, Anderson (Estado, 1979) y Vilar ("Primitivos", 1980) ponen de relieve la inexistencia de una estructura social y productiva eficiente. Desde una perspectiva más cercana, Pascual y Sudrià ("Quiebra”, 1992) relacionan la pérdida de las colonias y la supresión del flujo metálico con la larga depresión que, en parte, explica el retraso en el proceso de industrialización del país. Por otra, Prados ("Pérdida", 1993) se inclina por una posición más discutible haciendo hincapié en los efectos positivos a largo plazo que supone la pérdida de los territorios de ultramar para el proceso de modernización del país.

${ }^{2}$ Véanse Irigoin, "Finance", 2000, y "Gresham", 2010; Mitre, Monedero, 1986; Matamala, "Descentralización”, 2001; Tedde y Marichal, Formación, 1994, y Jaramillo, Meisel y Urrutia, Continuities, 2001.

${ }^{3}$ Véanse Prieto y Haro, Historia, 2010. 
El presente artículo se desarrolla a lo largo de cuatro apartados, incluyendo el de conclusiones. En el primero se analiza el sistema monetario tradicional de base bimetálica y la política monetaria de carácter fiscal que se desprende del mismo. Asimismo, se estudia la lógica económica y la base metodológica sobre la que se sustenta la política monetaria tradicional. En último término, se exponen las crecientes dificultades de liquidez a las que se enfrenta el sistema una vez perdida la base metálica que ofrecen las remesas americanas. En el segundo apartado se explica la forma con la que el sistema monetario evita su colapso inmediato, no a través de la reforma, sino mediante una progresiva subordinación a la moneda francesa. En el tercer epígrafe se analiza la reforma monetaria del trienio constitucional. Se estudian los proyectos haciendo hincapié en las virtudes y los límites de una reforma que por primera vez pretendía imprimir un cambio de fondo al sistema monetario tradicional. Finalmente, en la conclusión se subrayan los factores explicativos del retraso en el proceso de transición monetaria en la España de la primera mitad del siglo XIX y el alcance real de la reforma monetaria del trienio, resaltando los factores endógenos y las dificultades del marco general en el que se desarrolla y que propician los límites de la reforma monetaria liberal propuesta en la década de 1820.

\section{LOS VIEJOS HÁBITOS MONETARIOS ${ }^{4}$}

España se ha convertido desde el siglo XVI en el proveedor de metales preciosos para los mercados europeos. ${ }^{5}$ Sin embargo, este hecho, no significa que España disponga de un sistema monetario moderno o de instituciones financieras desarrolladas que permitieran la irrupción del sistema capitalista en la economía española, más bien todo lo contrario. Durante el siglo XVI España despliega un modelo de conquista netamente feudal, ${ }^{6}$ para más tarde, a partir de la segunda mitad del siglo XVI, consolidar un sistema económico, en consonancia con la noción de antiguo régimen, cuyo eje descansa en las remesas metálicas y su compleja gestión por parte de la corona a modo de fuente de rentas. El fuerte impulso que experimenta el comercio con América en el siglo XVIII, a través de la producción de plata y la liberalización comercial de $1778,{ }^{7}$ sólo tiene efectos muy limitados para la economía peninsular, sin llegar a modificar su estructura tradicional.

\footnotetext{
${ }^{4}$ Conceptos utilizados por Rojo en el prólogo de la última edición de la obra de J. Sardà con motivo del 50 aniversario de la primera edición. Véase Sardà, Política, 1998, p. VI.

${ }^{5}$ Sobre metales preciosos, rentas americanas y mercados europeos, véanse Kriedte, Feudalismo, 1994, pp. 47-68; Tepaske y Kelin, Ingresos, 1986-1988, y Hamilton, Tesoro, 2000.

${ }^{6}$ Sobre el modelo de conquista colonial castellana, véase Vilar, "Tiempo", 1980.

${ }^{7}$ Véase Fisher, Commercial, 1985.
} 
El sistema tradicional se asienta sobre la base bimetálica o doble standard de oro y plata, ${ }^{8}$ en el que los dos metales son acuñados libremente en las casas de moneda bajo tarifas de compra establecidas por las autoridades monetarias. El sistema se compone de dos áreas estrechamente interdependientes, y caracterizado por la elevada dependencia de la región peninsular respecto de la americana. Tanto las casas de moneda de la península dedicadas a la acuñación de oro y plata, Madrid y Sevilla, como las americanas, destacando las de la ciudad de México y Lima, elaboran una moneda de alto valor intrínseco ${ }^{9} \mathrm{y}$ aplican unos elevados derechos de retención.

La moneda fuerte, o bien toma el camino de la exportación, o es retirada de la circulación configurando parte de los tesoros particulares, ${ }^{10}$ siendo así presa de un intenso proceso de tesaurización. ${ }^{11}$ La corona, principal protagonista del drenaje exterior, dedica las rentas americanas al mantenimiento de la onerosa política militar ${ }^{12}$ y diplomática europea, condenando la economía española a una continua escasez de metales preciosos y a una escasa circulación de monedas de oro y plata, agravada de forma progresiva por el persistente déficit crónico en la balanza comercial española. ${ }^{13}$

Las autoridades monetarias, con el aparente fin $^{14}$ de hacer frente a la salida de capital sin contrapartida, se empeñan en una política defensiva de prohibiciones a las exportaciones monetarias con parcos resultados. ${ }^{15}$ Las reiteradas disposiciones sobre permisos, pagos de derechos y guías de circulación se muestran como ineficaces medidas para disuadir la masiva exportación de capitales. La contradicción reside en que la exportación de metales se fundamenta en la propia política monetaria tradicional consistente en bajas tarifas de las casas de moneda, altos derechos de acuñación y equivalencias oro/plata en torno a $1 / 16.5$, sensiblemente desfasadas respecto de Europa, subvalorando la plata, y, por consiguiente, defendiendo en el país las existencias de oro, aunque dicha política empujase la plata a la exportación a gran escala, legal a cargo del Banco de San Carlos, o

${ }^{8}$ Véase Mateu, Moneda, 1946, p. 270.

${ }^{9}$ Véase Cipolla, Odisea, 1999.

${ }^{10}$ Manuel Lamas, ensayador mayor del reino que estimó que la moneda circulante en el país en 1772 ascendía a 4886229.132 reales y que la escondida podía suponer alrededor de la mitad de dicha cifra, esto es, 2443000.000 reales. Véase Vadillo, Reflexiones, 1846, p. 51.

${ }^{11}$ Fenómeno estudiado por Marx, Contribución, 1976, pp. 156-168.

${ }^{12}$ Véase Ehrenberg ("Zeitalter", 1922) para analizar los caminos de la plata, y Flynn ("Desarrollo", 1984) para contrastar la relación entre metales y gastos de guerra. Sobre la importancia de los metales preciosos para la monarquía española, véase Espina, "Oro", 2001.

${ }^{13}$ Véase Fontana, Crisis, 1992, pp. 272-276.

${ }^{14}$ Sobre el Banco de San Carlos y el monopolio de exportación de moneda, véanse Canga, Diccionario, 1833, y Tedde, Banco, 1988.

${ }^{15}$ Archivo General de Simancas (en adelante AGS), Dirección General de Rentas, Extracción de moneda 1564-1806, legs., 4880-4942. 
ilegal mediante las sacas. La política monetaria tradicional no obedece a principios económicos y monetarios modernos, sino más bien, a razones de orden fiscal y defensa de los depósitos tradicionales, considerando el ramo de la acuñación como un instrumento más de su política de ingresos fiscales. En definitiva, no se tiene como objetivo la consecución de una política monetaria que se preocupe por la estabilidad de los precios y el crecimiento económico del país. Es decir, preserva un sistema monetario incapaz de impulsar el crecimiento económico peninsular a través de una oferta monetaria que proporcione la liquidez suficiente para cubrir los tráficos y garantizar las inversiones. ${ }^{16}$

La política monetaria tradicional, a pesar de que pueda considerarse como una política absurda y antieconómica, no deja de responder a las exigencias y necesidades de la economía tradicional. A lo largo de la primera mitad del siglo XIX, y probablemente hasta la reforma monetaria de Beltrán de Lis de $1848,{ }^{17}$ la situación del sistema monetario español, siguiendo a Keynes, ${ }^{18}$ se podría caracterizar como el resultado de la incapacidad del Estado central para responder adecuadamente a la demanda de dinero que, de manera natural, surge del propio proceso de transformación económica. ${ }^{19}$

En la España de principios del siglo XIX predomina la economía de subsistencia que restringe el ámbito mercantil a ciertos bienes que no pueden obtenerse de forma directa (gastos suntuarios, armas, etc.) y que deben ser satisfechos en moneda. El consumo ordinario apenas está mercantilizado y las rentas y los impuestos se atienden mayoritariamente en especie, y aun cuando comience su monetización, esta es todavía muy lenta y está poco implantada. Para el caso español, no se dan las condiciones para que se produzca la generalización del uso del dinero en los intercambios. Este proceso se relaciona directamente con la dinámica de separación entre productores y medios de producción y la difusión del trabajo asalariado como forma normal de organización de la producción. ${ }^{20}$ El desarrollo del

${ }^{16}$ Véase Sardà, Política, 1998, p. 23.

${ }^{17}$ Véase Prieto y Haro, Reformas, 2004.

${ }^{18}$ Keynes describe la economía de intercambio real como aquella que "usa dinero, pero sólo como un lazo neutral entre transacciones de cosas y activos reales, y no le permite participar en los motivos o decisiones". Es decir, la definición de economía de los intercambios reales vendría en contraposición de lo que sería una economía monetaria en la que el dinero "juega su propio papel y afecta a los motivos y decisiones, [...] de forma que el curso de los acontecimientos no puede predecirse, tanto en el corto como en el largo plazo, sin un conocimiento del comportamiento del dinero a lo largo del proceso". Véase Chick, Macroeconomía, 1990, p. 22.

${ }^{19}$ En las economías preindustriales, la moneda, aunque exista en mayor o menor medida, no desempeña un papel central en la vida económica. Asimismo, en estas economías las funciones convencionales del dinero se encuentran sensiblemente alteradas por los elevados índices de atesoramiento.

${ }^{20}$ Véanse Prieto, Agricultura, 1988, y Sistema, 2008. 
trabajo asalariado y la consiguiente mercantilización de la vida económica sólo tuvieron cierta importancia en algunas áreas geográficas específicas en las que aparecieron actividades industriales y comerciales de cierta envergadura, como es el caso de Cataluña, Valencia, Málaga o "el Marco del Jerez" en Cádiz. ${ }^{21}$ Sin embargo, el escenario de escasa transformación no impide que comiencen a manifestarse algunos cambios, aunque aislados y de forma inconexa, hacia lo que podríamos denominar una economía moderna.

En este contexto la sustitución del sistema monetario tradicional se hace condición necesaria para la propia modernización de la economía en general. ${ }^{22}$ Sucedió en la Barcelona de las décadas de 1830 y 1840 , cuando, como detalla Paradaltas, ${ }^{23}$ los sectores implicados se movilizaron y, con su diputación al frente, optaron, contra Madrid, por atender la demanda de dinero existente mediante la articulación de una política monetaria eficaz, en la que se combinaba con acierto el aumento de las tarifas de la Casa de Moneda de Barcelona con la devaluación metálica de la nueva moneda acuñada para aumentar la liquidez y evitar las sacas y la circulación de la moneda foránea aunque el proceso no estuviese exento de problemas derivados de la acuñación excesiva de moneda de cobre. Esta es la conclusión más importante que se desprende del análisis de la política monetaria practicada a lo largo de la primera mitad del siglo XIX. Porque, aunque puede probarse que a partir de la Ley de Beltrán de Lis de 1848 las cosas empezaron a cambiar, el retraso que provocó el marasmo de la primera mitad del siglo resultó de muy difícil recuperación.

En definitiva, la política monetaria tradicional, lejos de favorecer la modernización del país, ${ }^{24}$ se convertirá en un serio obstáculo al mantener una oferta monetaria muy restrictiva. A la política monetaria tradicional hay que unir la escasa implantación de instituciones financieras y bancarias en cuanto a su número y variedad, en relación con lo que acontece en otras áreas europeas, constituyendo su carencia un serio obstáculo para el crecimiento y desarrollo de la economía peninsular. Esta política monetaria se mantiene gracias a la continua llegada del flujo metálico americano que durante el siglo XVIII alivia los efectos restrictivos que sobre la oferta monetaria produce esta vieja política. Sin embargo, en el siglo XIX, la

${ }^{21}$ Para el caso de Cataluña, véanse Maluquer, "Índice", 1994, y Pascual y Sudrià, "Industrialización”, 2008, y de Andalucía, véase Maldonado, Formación, 1999.

${ }^{22}$ Hay trabajos teóricos recientes que han remarcado la importancia del desarrollo financiero y monetario en las primeras fases de modernización y sus efectos sobre el crecimiento, véanse Rousseau y Sylla, "Financial", 2003, y "Financial", 2006; Bordo y Rousseau, "Legal-political", 2006, y Levine, "Finance", 2005.

${ }_{23}^{23}$ Véanse Paradaltas, Tratado, 1847, y Pascual, "Moneda", 2004.

${ }^{24}$ Para Sardà (Política, 1998, p. 21) este problema mantiene las iniciativas capitalistas aherrojadas. 
independencia de los territorios de ultramar, y con ello el colapso de las importaciones de capitales, y la crisis de la monarquía absolutista, abren ineludiblemente el debate de la necesaria transición y reforma del sistema monetario.

\section{Agotamiento y SUbORdinación a Francia}

El sistema monetario a principios del siglo XIX es fiel reflejo del marco monetario impuesto por los Borbones desde el primer tercio del siglo XVIII. Con la llegada de la dinastía borbónica se impulsa un vasto proyecto de centralización y reorganización del sistema monetario y de acuñación, ${ }^{25}$ proyectado con la intención de recomponer la política monetaria tradicional. En cambio, durante el último tercio del siglo el impulso reformista se irá agotando paulatinamente, perdiéndose cualquier atisbo de sensibilidad reformista, aunque fuera dentro del marco tradicional. ${ }^{26} \mathrm{El}$ sistema peninsular se sitúa en un marco de inestabilidad creciente sin reforma. ${ }^{27}$

Esta debilidad monetaria se convierte en un elemento clave en el proceso de progresiva subordinación frente a la política monetaria francesa. Durante gran parte de la primera mitad del siglo XIX, la moneda española está fuertemente mediatizada por los acontecimientos monetarios del país vecino. El proceso de subordinación y dependencia monetaria responde fundamentalmente a dos causas: por una parte, una razón que podemos considerar como endógena, se deriva de la impotencia del sistema monetario nacional por garantizar una liquidez interior suficiente. Aunque la demanda interna, tomada de forma agregada, seguía siendo a principios del siglo XIX muy baja, las plazas comerciales y los primeros focos manufactureros generan una creciente tensión sobre la estrecha oferta monetaria. De este modo, la moneda francesa se convierte en un recurso que alivia, aunque sólo en parte, el grave problema de la falta de liquidez. Por otra parte, se añade un motivo que podemos considerar exógeno, el interés por parte de Francia de que el sistema monetario español asumiese parte del costo de su propia reforma monetaria emprendida con la revolución de 1789. ${ }^{28}$ Esto es, que España legalizando la circulación de numerario francés en su interior absorbiese una parte significativa de la moneda prerrevolu-

\footnotetext{
${ }^{25}$ García ("Estabilización”, 2000) sostiene la tesis de la estabilización monetaria anterior a los borbones.

${ }^{26}$ El último intento de estabilización lo protagoniza Cayetano Soller mediante la desamortización de obras pías en 1798 .

${ }^{27}$ Para ver los crecientes problemas recaudatorios, véanse Barbier y Klein, "Prioridades", 1985, y Fontana, Quiebra, 1971.

${ }^{28}$ Véanse Francisco, Moneda, 2000, pp. 211-212; Darnis, Monnaie, 1988, y Saint, Histoire, 1983.
} 
cionaria, evitando al sistema monetario francés los costos derivados de su retirada y refundición. Parece que lo más acertado sea el ponderar adecuadamente, por una parte, la responsabilidad española en el sostenimiento de esta política monetaria, como elemento principal y, por otra, desempeñando un papel complementario, la presión que Francia presumiblemente ejerció para que esta se mantuviese ${ }^{29}$ Este fenómeno de subordinación y dependencia monetaria es clave en la transición de nuestro sistema monetario ya que se va a convertir en una cuestión presente a lo largo de toda la primera mitad del siglo XIX, que no termina por resolverse hasta la Ley Monetaria de 1848.

Desde una perspectiva histórica, el proceso de subordinación respecto a Francia tendrá un impulso decisivo con la guerra de independencia. Los enfrentamientos bélicos, que tradicionalmente se habían desarrollado fuera de nuestras fronteras, se trasladan de lleno a la península. La guerra muestra la crisis del régimen y el país se organiza, en parte, de forma novedosa a través de las denominadas juntas como instrumentos políticos con los que satisfacen la ausencia de un poder central. ${ }^{30}$ Por una parte, desde el nuevo gobierno, se procura hacer frente a la situación estimulando la acuñación mediante la proliferación de talleres monetarios. Las acuñaciones de moneda patriótica aunque sean limitadas, irregulares y estén muy restringidas a causa del bloqueo, estimulan sensiblemente la oferta monetaria nacional. Y, por otra parte, con la presencia de ejércitos foráneos se impulsa la introducción de moneda extranjera en el sistema monetario peninsular. Asimismo, el bando francés, además de impulsar las acuñaciones propias de José I, impone la circulación de la moneda imperial con equivalencias oficiales. Esta equivalencia supone un tipo de cambio desfavorable para la circulación de la moneda española, ya que esta mantenía, en relación con el valor facial atribuido, un mayor contenido metálico por unidad. En el cuadro 1 se pueden observar los valores intrínsecos de la moneda francesa, el tipo de cambio oficial establecido y el grado de apreciación.

Con esta equivalencia, se hace efectiva la Ley de Gresham: la plata española tiende a ser retirada de la circulación por parte de los particulares, siendo sustituida progresivamente por el numerario francés. Las Cortes, en sus primeras iniciativas, ${ }^{31}$ intentan retirar la moneda francesa y actuar como dique frente a la nueva normativa monetaria; sin embargo, con la

${ }^{29}$ Véanse Artola, Antiguo, 1991, p. 265, y Sardà, Política, 1998, p. 43.

${ }^{30}$ Véanse Amat, Balances, 1813; Salat, Tratado, 1818, y Goig, Moneda, 1974.

${ }^{31}$ Decreto del 4 de junio de 1811. 


\section{CUADRO 1. TABLA OFICIAL DE CAMBIO DE LA MONEDA FRANCESA Y TIPO DE CAMBIO DE MERCADO}

\begin{tabular}{lccc}
\hline & $\begin{array}{c}\text { Tipo de } \\
\text { cambio oficial }\end{array}$ & $\begin{array}{c}\text { Equivalencia } \\
\text { de mercado }\end{array}$ & $\begin{array}{c}\text { Grado de } \\
\text { apreciación } \\
\text { Moneda francesa }\end{array}$ \\
& $(A)$ & $(B)$ & \\
1/4 de franco & 0.882 & 0.705 & 1.251 \\
1/2 de franco & 1.823 & 1.705 & 1.069 \\
1 franco & 3.705 & 3.411 & 1.086 \\
2 francos & 7.470 & 6.823 & 1.094 \\
5 francos (napoleón) & 18.705 & 17.058 & 1.096 \\
20 francos & 75.000 & 74.176 & 1.011 \\
40 francos & 150.000 & 148.352 & 1.011 \\
1 libra y 10 sueldos & 5.529 & 4.941 & 1.119 \\
1/2 luis de plata & 11.058 & 9.882 & 1.119 \\
1 luis de plata & 22.176 & 19.764 & 1.122 \\
1 luis de oro de 24 libras & 88.882 & 87.147 & 1.019 \\
1 luis de oro de 48 libras & 177.823 & 174.294 & 1.020 \\
\hline
\end{tabular}

Fuente: elaboración propia con base en Vadillo, Reflexiones, 1846, pp. 30-36, del valor de las piezas francesas en circulación de 1808 a 1846 y expresadas en reales de plata.

aprobación de las equivalencias de Cádiz, ${ }^{32}$ acaban aceptando la dualidad monetaria.

Esta situación monetaria anómala, que se repite en otras muchas naciones europeas durante las guerras napoleónicas y que tiende a remitir cuando la contienda concluye, en el caso español queda enquistada. La circulación legal de moneda francesa con valor intrínseco menor al facial conlleva la sustitución del numerario español, que torna en masa cuando se flexibiliza al máximo los requisitos de legalización ${ }^{33}$ y la divergencia en el tipo de cambio progresivamente se acentúa.

En definitiva, la economía española pierde la oportunidad de llevar a cabo la transformación de su sistema monetario, mientras su estructura tradicional entra en una fase de decadencia irreversible tras el colapso de los caudales metálicos de ultramar ${ }^{34}$ y la caída de las rentas interiores. La

${ }^{32}$ Decreto del 3 de septiembre de 1813.

${ }^{33}$ Decreto del 10 de noviembre de 1818.

${ }^{34}$ Para la balanza comercial, véase Canga, Diccionario, 1833, y para remesas americanas para la etapa tardo-imperial, véanse Fontana, Crisis, 1992; Marichal, Bancarrota, 1999, y "Beneficios", 1997. 
ausencia de una respuesta eficiente a la crisis de liquidez precipita al país por la senda de la deflación y el estancamiento, abandonando a su suerte a los sectores económicos más activos y evitando el colapso monetario a través de la subordinación paulatina a Francia que vierte a la península su dinero predecimal con mayor grado de apreciación.

\section{LA REFORMA MONETARIA DEL TRIENIO CONSTITUCIONAL. \\ DEL REFORMISMO BORBÓNICO A LA POLÍTICA MONETARIA LIBERAL}

Los problemas monetarios se mantienen plenamente vigentes, e incluso muchos de ellos se han agudizado en el comienzo de la década de $1820,{ }^{35}$ aunque desde el punto de vista de los precios, el país todavía se encuentra a finales de la última fase alcista posbélica ${ }^{36}$ Las autoridades monetarias, que no garantizan una circulación monetaria nacional estable y suficiente, estrechan sus dependencias respecto de la moneda francesa, mantienen una abultada circulación de cobre y no acaban de resolver el problema de los vales reales, ${ }^{37}$ manifestándose incapaces de generar un mínimo clima de confianza, que es la base de los sistemas monetarios modernos.

El objetivo general del trienio se centra en el crecimiento económico, y para ello se ponen en marcha las reformas fiscal y comercial. Ambas encaminadas a lograr el equilibrio presupuestario y exterior, respectivamente, que permitiese a la economía nacional disponer de una nueva base saneada. Estos son los más importantes condicionantes sobre los que pivota la oferta monetaria. La reforma del sistema monetario debe analizarse como parte de este nuevo contexto general, que a su vez actúa a modo de condicionante.

El trienio liberal despliega la iniciativa monetaria tratando, por primera vez, de alcanzar objetivos modernos. Nos encontramos ante una reforma ${ }^{38}$ que pretende abandonar los viejos hábitos que impedían que se desarrollase adecuadamente el sistema de mercado, que aunque de forma muy limitada, comienza a apuntar. El régimen liberal enfoca el problema monetario con amplitud y eso pasa por unificar y homogenizar el sistema monetario peninsular, establecer la nueva planta de las casas de moneda,

${ }^{35}$ Véase Gil, Trienio, 1980, p. 1.

${ }^{36}$ Acerca de los datos de nivel de precios, véanse Sardà, Política, 1998, pp. 61, 302-305; Bustelo y Tortella, "Monetary”, 1976, y Fontana, Crisis, 1992, p. 278. Véase también Nogués, más escéptica en cuanto a la intensidad de la deflación durante la primera mitad del siglo XIX mediante análisis comparativo europeo, Nogués, "Análisis", 2005.

${ }^{37}$ Real decreto del 15 de agosto de 1818 . Plan de encaje de los vales reales en deuda nacional, Martín de Garay.

${ }^{38}$ Véase Haro, Reforma, 2006. 
acometer la retirada del numerario francés para poder disponer de una política monetaria propia y transformar las viejas instituciones monetarias haciéndolas más idóneas para los nuevos objetivos. En definitiva, fijar una nueva política monetaria que situase en el centro de su acción el estímulo sobre una oferta monetaria decreciente ${ }^{39}$ desplazando de sus objetivos la preocupación de la corona por la fiscalidad. Con objeto de financiar la reforma y conseguir un mínimo nivel de liquidez, al estar las remesas americanas interrumpidas y el crédito nacional agotado, se recurre a la negociación de empréstitos exteriores ${ }^{40}$ como shock monetario que actuase a modo de catalizador y sostén presupuestario mientras se aprueba y aplica la reforma fiscal.

Los debates parlamentarios de carácter monetario se desarrollan, en su mayor parte, en cuatro iniciativas que serán aprobadas a lo largo de las legislaturas de 1820, ordinaria de 1821 y extraordinaria de 1821: a) nueva moneda constitucional; $b$ ) reforma de las casas de moneda para convertirlas en fábricas nacionales de moneda, que incluye la abolición del señoreaje; $c$ ) transformación de la Junta de Comercio y Moneda en la Junta Directiva de Moneda, y $d$ ) el proyecto de resello nacional. A lo largo de las sesiones parlamentarias que tratan las controversias monetarias se advierte la presencia de los tres grupos políticos dentro de las Cortes: ${ }^{41}$ los serviles; el ala moderada del liberalismo, mayoritaria en las comisiones parlamentarias responsables de la redacción de los proyectos, y los liberales exaltados.

Un hecho relevante, y que se manifiesta a modo de lastre en cuanto a la posibilidad de poder imprimir un mayor grado de transformación en el sistema monetario a través de la reforma, consiste en el desfase teórico y la relativa desconexión con los debates monetarios que se plantean en la época en otros países avanzados. Nos referimos específicamente a los debates monetarios ingleses, y en menor medida franceses, de la segunda mitad del siglo XVIII y el primer tercio del siglo XIX ${ }^{42}$ en torno a las cuestiones relacionadas con la moneda metálica y la banca. La suspensión de la

${ }^{39}$ Sigue siendo un reto mayor el determinar con exactitud la oferta monetaria durante esta etapa. El último esfuerzo reseñable es el realizado por Tedde (“Oro", 2009, pp. 211-252), realizando estimaciones alternativas de la cantidad de oro y plata tomando como base los datos de García-Baquero, Comercio, 2003; Morineau, Incroyables, 1985, y Cuenca, "Statistics", 2008. El cuadro resultante ofrece un monto descendente desde los 4432 millones de reales en 1793 hasta los 2402 millones de 1850. Ya con anterioridad Sardà había estimado en torno a 3 000-4 000 millones de reales la oferta monetaria a inicios del siglo XIX con base en los datos reflejados en Anónimo, Breve, 1862. La gran dificultad del periodo se centra en la determinación de la cantidad de salidas de metálico.

${ }^{40}$ Véase Moral, Hacienda, 1975, pp. 178-192.

${ }^{41}$ Véase Gil, Diccionario, 2011.

${ }^{42}$ Para seguir los debates monetarios de la época, y a sus protagonistas, desde la voladura del pensamiento mercantilista hasta el debate del bullion, véanse O'Brien, Economistas, 1989, y Brunhoff, Oferta, 1975. 
convertibilidad efectuada por el Banco de Inglaterra en 1797, la inflación de principios del siglo XIX, la caída en los tipos de cambio, el alza en el precio del oro y los efectos provocados por el bloqueo durante las guerras napoleónicas provocan amplias discusiones en la sociedad inglesa que desembocan en el informe del comité seleccionado sobre el alto precio del lingote de oro en $1810 .^{43}$

Para el caso de España, durante los debates monetarios en Cortes a través de las respectivas comisiones se pone de manifiesto el alejamiento del país de los problemas monetarios europeos. Sin caer en un erróneo anacronismo, y aun considerando el caso inglés como único, se percibe, siguiendo los debates parlamentarios, una clara falta de sintonía con los posibles vectores de modernización.

Guillermo Oliver, ${ }^{44}$ en el debate de la nueva moneda constitucional, defiende la tesis de que "el dinero es una mercadería" ${ }^{45}$ como todas las demás. Juan Antonio Yandiola ${ }^{46}$ en el debate del arreglo de las casas de moneda de la nación, pone de relieve la paradoja española consistente en el hecho de que siendo cosecheros casi exclusivos de oro y plata no sacamos provecho de tal circunstancia, tratando la cuestión monetaria en términos de fomento de una manufactura ${ }^{47}$ y reduciendo el problema a un retraso tecnológico en la fabricación. En otro pasaje hace constar que: "El dinero en sí nada produce y encerrado en las arcas es un objeto de zozobras [...] la moneda no debe tener otro valor que el que significa y le da su ley respectiva." ${ }^{48}$ Todo para terminar reafirmándose en la tesis del dinero mercancía. José María Moscoso, ${ }^{49}$ en el debate de la reforma de

${ }^{43}$ Los debates en torno al bullion en Inglaterra (David Ricardo, Boyd, Wheatley, Lord King, Henry Thornton y Robert Torrens, entre otros) se convierten en debates monetarios modernos predecesores de los partidarios y detractores de la Currency School y la Banking School. En cuanto a los debates de libre emisión, véase White, Free, 1992.

${ }^{44}$ Guillermo Oliver y Salvá (Palma, 18 de marzo de 1775-Barcelona, 1 de agosto de 1839). Desde 1808 destaca como activo comerciante en Tarragona y Barcelona, siendo vocal de la Junta Superior de Cataluña durante la guerra de independencia. Publicó Memorias económico-políticas, Tarragona, 1820. Diputado a Cortes por Cataluña, en 1820-1822, y alcalde constitucional de Barcelona en 1837.

${ }^{45}$ Archivo Histórico del Congreso (en adelante AHC), Diario de Sesiones, Legislatura ordinaria de 1820, t. II, p. 1369, y Diario de Sesiones, Legislatura extraordinaria de 1821, t. I, p. 733.

${ }^{46}$ Juan Antonio Yandiola (1786-París, 8 de enero de 1830). Oficial de la Secretaría de Hacienda de Indias, que en 1811 remite desde México un oficio a las Cortes, que contiene una exposición sobre el estado de Nueva España, y dos papeles, titulados Informe biográfico reservado y Plan de una visita general, que convendría practicar en el reino de la Nueva España. Diputado a Cortes por Vizcaya, en 1820-1822. Tesorero general de la nación, en 1822-1823, y ministro de Hacienda con Calatrava.

${ }^{47}$ AHC, Diario de Sesiones, Legislatura ordinaria de 1821, t. I, p. 474.

${ }^{48}$ AHC, Diario de Sesiones, Legislatura extraordinaria de 1821, t. III, p. 2395.

${ }^{49}$ Moscoso de Altamira y Quiroga, José María. Conde de Fontao. Alcalde del Ferrol, diputado a Cortes por Galicia, en 1820-1823; miembro de la diputación permanente de Cortes, en 1821, y ministro de la Gobernación de la península en 1822. 
las cecas, indica como posible delito la desviación del intrínseco sobre el nominal. ${ }^{50}$ Lucas Alamán, ${ }^{51}$ en la misma discusión, plantea la experiencia inglesa no como posible vía para explorar la reforma del sistema nacional, sino como útil ejemplo para combatir la entrada masiva de falsos medios luises resellados, ${ }^{52}$ para a continuación situarse en una defensa cerrada del concepto de dinero mercancía. ${ }^{53}$

Al igual que Lucas Alamán, José María Queipo de Llano, conde de Toreno, presenta la experiencia británica pero a modo estrictamente descriptivo ${ }^{54}$ Concluye indicando que este tipo de iniciativas en España no son posibles por la falta de costumbre en el manejo de papel moneda y el descrédito que este tipo de soportes tienen en el país.

En definitiva, los debates monetarios no están acompañados de la necesaria tensión teórica que hubiese permitido elaborar planteamientos reformistas más allá de la mera estabilización y reajuste del sistema monetario nacional, manteniendo sólo alguna referencia teórico-práctica con el modelo francés de $1803 .{ }^{55}$ Incluso con el caso francés se dan profundos divorcios relativos a la adopción del sistema métrico decimal o la devaluación metálica. Los límites teóricos darán como resultado una serie de proyectos con cercenado alcance reformista.

La primera iniciativa que se acomete consiste en la recuperación de lo establecido en la Constitución de Cádiz, para a continuación decretar la nueva moneda constitucional. En el capítulo VII de la carta magna, en su

${ }^{50}$ AHC, Diario de Sesiones, Legislatura ordinaria de 1821, t. I, p. 737: "la moneda [...] tiene dos valores: el natural y el representativo: el valor natural no es más que el de la pasta; pero el valor representativo es el que le da la ley el cual debe fijarse en proporción al primero [...] así cuando el valor representativo es superior al legal [...] puede decirse que comete un robo".

${ }^{51}$ Lucas Alamán (Guanajuato, 18 de octubre de 1792-México, 2 de junio de 1853). Cursa física y química en la Escuela de Minería de México. Diputado por Guanajuato a las Cortes, en 1820-1822, en las que fue redactor del proyecto americano finalmente rechazado por el parlamento. En 1834, tras el pronunciamiento de Bustamante ocupa la presidencia de la república. Publica Dictamen sobre el importante ramo de la minería, 1819, Causas de la decadencia de la minería en Nueva España, 1821, La independencia mejicana, disertaciones históricas, 1844, e Historia de Méjico, 1849.

${ }^{52}$ AHC, Diario de Sesiones, Legislatura extraordinaria de 1821, t. I, p. 751: "allí se creó una moneda llamada bank-notes [...] un verdadero papel moneda plata. El objeto que aquel gobierno se propuso, fue el de impedir la extracción de numerario y lo logró completamente pues nadie llevaba al continente lo que costaba más de lo que por ello podía dar: pero no se notaba que por ello se introdujese esta moneda de fuera a modo de falsificación."

${ }^{53}$ AHC, Diario de Sesiones, Legislatura extraordinaria de 1821, t. III, p. 2398: "según los principios de economía política, la moneda no es otra cosa más que un género comerciable, o sea un producto fabril como las manufacturas de algodón o cualquier cosa [...] para que la moneda tenga confianza pública, es preciso que su ley y su peso sean la que debe ser".

${ }^{54}$ AHC, Diario de Sesiones, Legislatura extraordinaria de 1821, t. I, p. 705: "Los Bancos de depósito facilitaron (en los casos de Hamburgo y Holanda) todas las operaciones y emitieron papel a su nombre [...] En Inglaterra con otro motivo se trató de esto por lo que se experimentó en aquella nación con el aumento del valor del oro."

${ }^{55}$ Ley del 7 de abril de 1803. 
artículo 131, apartados 13, 19 y 20, se delimitan las funciones monetarias a desempeñar por las Cortes. Asimismo, la nueva moneda constitucional ${ }^{56}$ debe servir como instrumento para los intereses nacionales, y no como fuente de rentas de la corona. Este elemento es clave al permitir actuar sobre la moneda sin presiones patrimoniales.$^{57}$ La nueva moneda constitucional nace así sin las pesadas ataduras del antiguo régimen, como nuevo numerario símbolo de la nación, aunque finalmente los cambios propuestos en los troqueles acaban siendo discretos y moderados. El decreto del 1 de mayo de 1821, si bien, por una parte, incluye en la leyenda el término de constitución y se utiliza el castellano, por otra, mantiene en la simbología el Toisón, el escudo abreviado y las grandes armas, y en la leyenda la expresión "por la gracia de Dios". La moderación del triunfo liberal queda registrada en el anverso y reverso de la nueva moneda constitucional y se explica por la apuesta política del acuerdo con la corona, reforma pactada, y las reservas ante cambios sustanciales en la fisonomía de la moneda que pudieran afectar en su valoración comercial exterior, ${ }^{58}$ poniendo como ejemplo la experiencia del dólar estadunidense, duro español resellado, en el circuito monetario internacional. ${ }^{59}$

La segunda medida monetaria tiene que ver con la nueva planta de las casas de moneda, ${ }^{60}$ debate conocido en la época como arreglo de las casas de moneda. La finalidad del proyecto, expuesta en el expediente preparatorio, se centra en crear las condiciones necesarias para que los establecimientos de la nación puedan competir con los extranjeros en las tareas de acuñación. Para tal fin, es preciso desbloquear los obstáculos que impiden la llevanza de pasta a las casas de moneda y establecer las normas precisas para que, a través de la reinversión productiva de ahorros, se pueda estrechar la brecha de atraso tecnológico que arrastran respecto de los principales centros europeos y que provocan un diferencial negativo notable en relación con los costos de braceaje y su consecuente plasmación parcial en las tarifas de compra. La urgencia de la medida viene motivada por la ruinosa situación contable, física y tecnológica en la que se encuentran estos establecimientos, así como lo recoge la intervención realizada por el contador ${ }^{61}$ de la Casa Nacional de la Moneda al superintendente general. Por este motivo, el decreto acomete la reforma en los siguientes

\footnotetext{
${ }^{56}$ Decreto del 1 de mayo de 1821.

${ }^{57}$ El concepto de Estado patrimonial aparece en Terrón, Sociedad, 1969, del que lo toma Valdeón en la obra de Parain, Feudalismo, 1972, p. 18.

${ }^{58}$ AHC, Diario de Sesiones, Legislatura ordinaria de 1820, t. II, p. 1369, y Legislatura ordinaria de 1821, t. II, pp. 903, 906.

${ }^{59}$ AHC, Diario de Sesiones, Legislatura ordinaria de 1820, t. II, p. 1368.

${ }^{60}$ Decreto del 25 de junio de 1821.

${ }^{61}$ Véase Durán, "Historia”, 1994, p. 107.
} 
términos: a) considerar las casas de moneda como fábricas de acuñación bajo inspección del gobierno, b) rebajar los derechos de retención a costos de fabricación, ${ }^{62} c$ fijar unas nuevas tarifas de compra en las que se recoge la supresión del derecho de señoreaje (véase cuadro 2), y $d$ ) establecer un sistema de reparto, a partes iguales, de potenciales ahorros al fomento de las fábricas y mejoras retributivas a los empleados.

Con estos objetivos se pretende convertir las viejas casas reales en modernas fábricas de acuñación, y estimular la deprimida oferta monetaria que con los procesos de emancipación, muy avanzados en las provincias de ultramar, han privado de la explotación de más de 200000000 de duros. ${ }^{63} \mathrm{El}$ modelo por el que se apuesta tiene como referencia la experiencia francesa de imponer como retención únicamente los costos de braceaje, desechando la alternativa inglesa, en la que no se repercute carga alguna, por estrechez de recursos públicos. ${ }^{64}$ Sin embargo, llama la atención la preocupación por parte de los ponentes de que la moneda española recupere cuanto antes su papel en el comercio internacional, siendo ahora suplantada progresivamente por monedas británicas y francesas. Es decir, el problema por la oferta monetaria peninsular se traslada a un problema de competitividad de la moneda española en los mercados internacionales, en especial el asiático. Esta prioridad saca del debate la controversia en torno a la estrecha oferta monetaria, trasladando su tratamiento al futuro proyecto de resello nacional y perdiendo así la oportunidad de mantener en la circulación interior buena parte del shock monetario derivado de la concreción de los primeros empréstitos extranjeros. ${ }^{65}$ Como señala uno de los ponentes: "los extranjeros que apetecen acuñar metales en España, no tienen por objeto emplear sus capitales en nuestros frutos para dejar el numerario entre nosotros: su fin es adquirir moneda española para hacer el comercio lucrativo en Asia, en cuyos países se admiten con una preferencia extraordinaria los duros españoles, ganando en este cambio un 20 por $100 "{ }^{66}$ La tesis no se refuta en la discusión señalando únicamente que alguna utilidad le reportará a la nación su tránsito y circulación por la península. En la gráfica 1 se puede observar el shock monetario que supone la iniciativa reformista.

El decreto plantea un proyecto de modernización de las infraestructuras de acuñación con el objeto de incentivar la productividad, elevar

${ }^{62}$ Braceaje, sueldos de empleados, conservación de máquinas, utensilios y establecimientos.

${ }^{63}$ AHC, Diario de Sesiones, Legislatura ordinaria de 1821, t. III, p. 2395.

${ }^{64}$ Lucas Alamán en AHC, Diario de Sesiones, Legislatura ordinaria de 1821, t. III, p. 2398.

${ }^{65}$ AHC, Serie de impresos, leg. 8, núms. 5 y 51. Dictamen de la Comisión de Hacienda sobre acunación de moneda procedente de barras y tejos de oro remitidos como parte del empréstito de 200000000.

${ }^{66}$ González Allende en AHC, Diario de Sesiones, Legislatura ordinaria de 1821, t. III, p. 2395. 


\section{CUADRO 2. RETENCIÓN}

$\begin{array}{lc}\text { Tipología } & \text { Retenida (porcentaje) } \\ & \\ \text { Oro nacional } & 1.24 \\ \text { Oro provincial } & 1.01 \\ \text { Plata nacional } & 3.08 \\ \text { Plata provincial } & 3.70\end{array}$

Nota: Precios de compra: 3070 reales por marco de oro fino y 182.5 reales por marco de plata de igual ley.

Fuente: Anónimo, Breve, 1862, p. 72.

el nivel tecnológico, reduciendo el braceaje y estimulando la llevanza de metales. Pero, en paralelo, se defiende la presencia de la moneda gruesa española en los mercados internacionales y se relativiza el problema de las sacas y sus efectos sobre la oferta monetaria interior. Esencialmente hay dos aspectos que el decreto no aborda y que son fundamentales para la pervivencia de la política monetaria tradicional. Un primer aspecto es la relación de equivalencia oro-plata y un segundo, el relativo al fino de la moneda. Respecto a la nueva equivalencia oficial, las tarifas de compra de los metales establecen una relación bimetálica de 1/16.7, por lo tanto, ligeramente superior a la establecida en la Ley de 1786 . De esta forma, la plata nacional permanece muy subvalorada si la comparamos con las distintas equivalencias que imperan en los países europeos de nuestro entorno, en especial con Francia que tras la reforma de 1803 había establecido una relación bimetálica 1/15.5. En relación con el fino de la moneda, no existen evidencias de que se produjesen disminuciones ni en la ley, ni en el peso de la moneda. El valor intrínseco de la nueva moneda constitucional permanece invariable con la reforma monetaria ${ }^{67}$ Respecto a este punto hay autores que han avanzado que la propia subida de las tarifas de compra de los metales suponía automáticamente una devaluación metálica de la moneda. ${ }^{68}$ Sin embargo, nada de esto se produjo. Ni en el decreto del 1 de mayo de 1821 ni en el correspondiente al 25 de junio de ese mismo año hay referencia alguna de modificación de la ley o el peso de la moneda, de tal forma que aunque se mejore la retribución de los metales llevados a las casas de moneda, la nueva moneda sigue teniendo las mismas características en peso y ley que las monedas preconstitucionales, que se siguen rigiendo por las Leyes de Tallas de 1772 y 1786. La subida de las tarifas de

\footnotetext{
${ }^{67}$ Véase Anónimo, Breve, 1862, p. 72.

${ }^{68}$ Véase Sardà, Política, 1998, p. 61.
} 
Am. Lat. Hist. Econ., año 19, núm. 2 (38), mayo-agosto, 2012, pp. 131-161

GRÁFICA 1. NIVELES DE ACUÑACIÓN 1814-1833.

CASA DE LA MONEDA DE MADRID
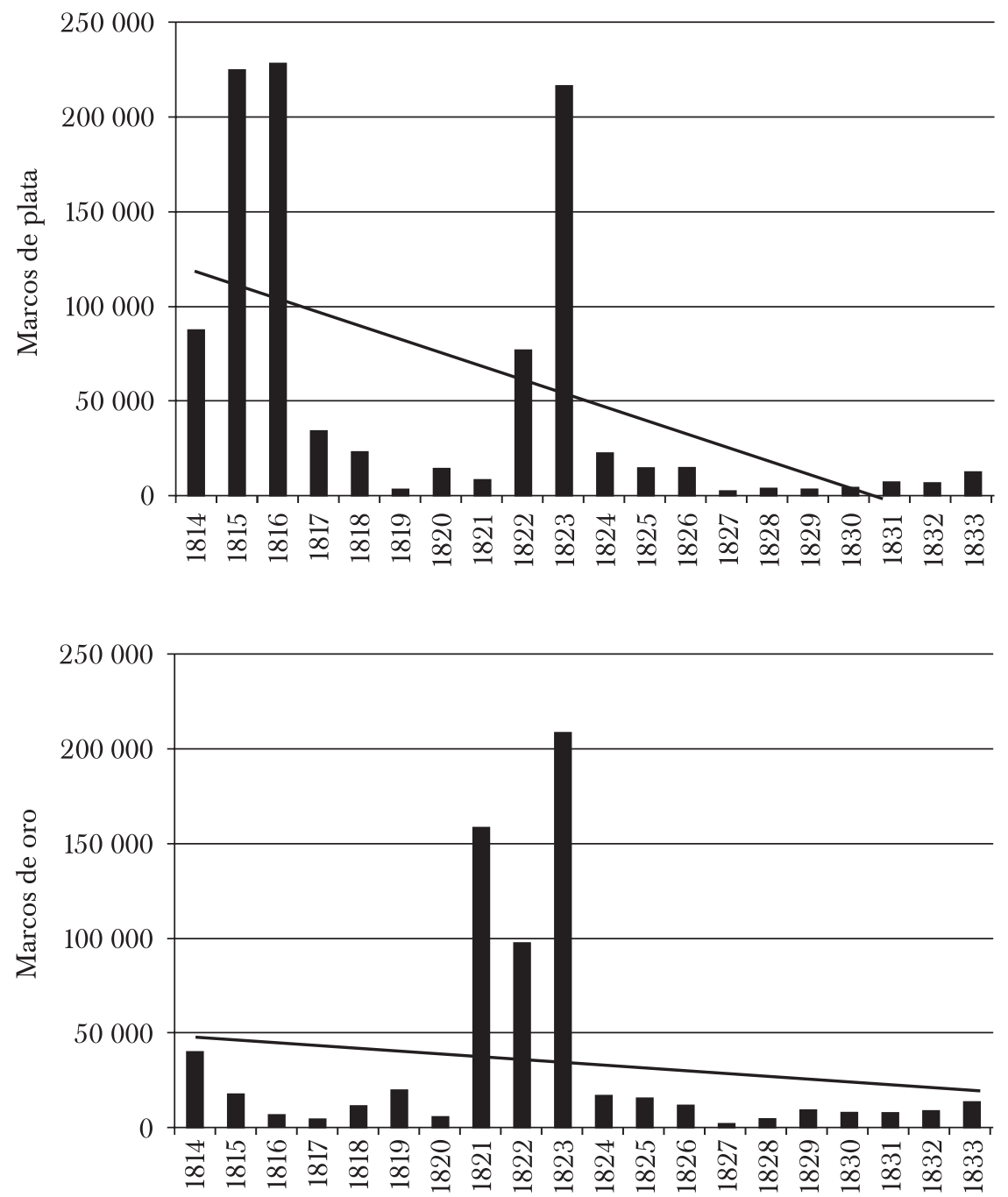

Fuente: elaboración propia con base en Murray, “Guía”, 1993, pp. 327, 334, y estableciendo una tendencia lineal. 
compra no se realiza a costa de la ley o el peso de la moneda, sino a cargo de los fondos liberados una vez abolido el derecho de señoreaje y aplicada la reducción de otras retenciones. Además, se cuenta con un estrecho margen de reservas propias de metales preciosos en pasta que mantienen en sus fondos las casas de moneda. ${ }^{69}$ La elevación de las tarifas de compra presumiblemente no hubiese significado un freno significativo a las exportaciones de metal ya que, a pesar de la mejor retribución de las pastas, el alto contenido del fino de las monedas seguía siendo una poderosa razón para continuar realizando las sacas sobre una moneda no devaluada.

La tercera iniciativa monetaria pretende la creación de la Junta Directiva de Moneda ${ }^{70}$ que venía a sustituir a la tradicional Real Junta de Comercio, Moneda y Minas, inhábil desde la asunción del sistema liberal. Con esta medida se pretende dotar al gobierno de una institución con carácter técnico que asesore y supervise los diversos proyectos de reforma encaminados a modernizar el sistema monetario. La finalidad era proporcionar al país una nueva institución monetaria capaz de dirigir las reformas con objetividad y rigor. ${ }^{71}$ Sus cometidos atienden prácticamente a todos los elementos relacionados con el ramo de la moneda: vigilar la uniformidad de la ley, peso y forma de las monedas; mejorar la elaboración monetaria; favorecer la difusión de nuevos conocimientos y técnicas en el ramo; formar las tarifas; proponer las supervisiones necesarias en las fábricas de acuñación; presentar anualmente memoria al gobierno, y proveer a este de todos los informes técnicos necesarios para ejecutar las reformas. Además, por primera vez, se considera la posibilidad de coordinar los asuntos monetarios peninsulares y americanos en una nueva concepción global y unitaria del sistema monetario nacional.

La cuarta medida, y probablemente la más compleja de ejecutar y controvertida, fue la encaminada a la retirada y resello ${ }^{72}$ de la moneda francesa que circulaba en España. Es el proyecto que contempla la unificación monetaria peninsular mediante la depuración del numerario francés y la supresión de las anteriores tarifas que permitían su circulación legal. El resello es la principal medida de política monetaria adoptada en el trienio. En la exposición de motivos se señalan como objetivos de la ley: "proponer los medios de impedir el curso de la defectuosa [moneda francesa], la

\footnotetext{
${ }^{69}$ Los apuntes contables ordinarios y descontados créditos y baxas constatan que los fondos de la Casa de la Moneda de Madrid en metales preciosos entre el 31 de diciembre de 1819 y el 30 de junio de 1822 se han reducido en 40\%. En AHN, FCC, leg. 7681, exp. 4.

${ }^{70}$ Decreto del 22 de noviembre de 1821.

${ }^{71}$ Las plazas que se habilitan para la formación de la Junta Directiva de Moneda son: química, grabado, ensaye, administración, cuenta y razón, maquinaria y un solo representante del gobierno.

${ }^{72}$ Decreto del 19 de noviembre de 1821.
} 
cual inundando toda la nación, la priva de la suya propia buscada en todas las partes del mundo, haciéndola objeto de especulaciones extranjeras, alimentando el fraude dentro de nosotros mismos, y causándonos en último resultado unos perjuicios incalculables en nuestros cambios, y un descrédito no pequeño". ${ }^{73}$ El problema, situándolo en torno a la falsificación y circulación defectuosa de moneda y las sacas, se centra en esta ocasión sobre la oferta monetaria interior. A través de los debates en Cortes podemos realizar una reconstrucción aproximada del montante de $\mathrm{M}$ considerado por los ponentes y la proporción de circulante francés sobre el total en millones de reales de plata ${ }^{74}$ (véase cuadro 3).

El conde de Toreno calcula la cantidad de moneda circulante a través de la comparativa con Francia e Inglaterra. Considera que Francia pudiera tener como materia circulante una cantidad aproximada a los 2250000 francos, mientras que Inglaterra tendría una cantidad muy superior, aunque no tanta en relación con su riqueza debido al mayor desarrollo crediticio y financiero. La cifra correspondiente a España se deduce ajustando el circulante al nivel de renta del país en la misma proporción que en Francia. En cuanto a los cálculos de Alamán, este toma como base las cifras aportadas por Jerónimo de Uztariz, de principios del siglo XVIII y por Jean-François de Bourgoing, para finales de la centuria, fundadas a su vez en datos del ministerio de Hacienda. Tras la depuración y ajuste aplicables a los cambios sufridos en los flujos metálicos americanos durante los últimos once años, y teniendo en cuenta un déficit anual en la masa monetaria circulante en Europa de alrededor de 10000000 de duros, termina concluyendo que el numerario circulante peninsular no puede ser menor a 1600000 reales de plata. No obstante, a pesar de estos datos los numerosos expedientes remitidos desde distintos consulados ponen en evidencia la escasez de numerario circulante en la península. A lo largo de los debates en comisiones se insiste en la inadecuada proporción entre circulante numerario y mercancías o efectos que se presentan en los mercados de la nación ${ }^{75}$ llegando el problema a tal punto que en varias provincias en vez de ventas sólo se hacen permutas de géneros con géneros. Sin embargo, aun estableciendo la controversia en torno a la oferta monetaria interior,

${ }^{73}$ AHC, Diario de Sesiones, Legislatura extraordinaria de 1821, t. I, p. 703.

${ }^{74}$ Llama la atención la urgencia por resolver un problema que en sí representa una escasa porción de la oferta monetaria. A nuestro entender, y pendiente de investigaciones en marcha al nivel de provincial de resello de moneda francesa, la proporción era significativamente más elevada que la registrada en actas parlamentarias. Esta disociación cabe atribuirla a dos razones: una, las dificultades estadísticas de los gobiernos liberales a la hora de cuantificar la realidad económica, y dos, a la deliberada voluntad del gobierno por rebajar su monto al tener que consignar en los presupuestos el coste de la operación, en particular el relativo a la indemnización a particulares ( $10 \%$ del total de la recogida).

${ }^{75}$ AHC, Diario de Sesiones, Legislatura extraordinaria de 1821, t. I, p. 737. 


\section{CUADRO 3. OFERTA MONETARIA Y MONEDA FRANCESA}

\begin{tabular}{lcc}
\hline Autor & $M^{\mathrm{a}}$ & Moneda francesa \\
& & \\
Conde de Toreno & 2.040 & $90-80$ \\
Lucas Alamán & $\geq 1.600$ & 100 \\
Juan Antonio Yandiola & s. d. & 90 \\
González Allende & s. d. & 160 \\
Antonio Barata & s. d. & $150-100$ \\
\hline
\end{tabular}

a Circulación de moneda metálica.

Fuente: AHC, Diario de Sesiones, Legislatura de extraordinaria de 1821, t. I, pp. 706-716.

la línea maestra del proyecto se centra en actuar exclusivamente sobre la moneda francesa, que aun siendo muy notable su circulación en las principales plazas comerciales ${ }^{76}$ sólo representa, con base en los datos oficiales, una parte menor del total de la oferta. Ya en la exposición de motivos se señala como objetivo fundamental romper la dinámica falsificación-sacas, situando en el centro de la acción reformista la moneda foránea. Esta es considerada como factor explicativo de las distorsiones en la oferta monetaria, en vez de efecto no deseado de una política monetaria tradicional de moneda fuerte, lo que hubiera obligado a dirigir la iniciativa reformista sobre la moneda nacional.

El proyecto elimina el sistema de tarifas de moneda extranjera, dejando libre la entrada y salida de dinero sin fijación de precio a las monedas exteriores, siendo desde este momento recibidas en las casas de moneda como pasta, según su ley y peso. Este planteamiento pasaba obligatoriamente por la abolición de la ley del 10 de noviembre de 1818, cédula bajo la cual se había realizado un intenso flujo monetario a favor de la moneda francesa en detrimento de la nacional al legalizarse medios luises defectuosos de difícil identificación, fácil falsificación y un peso hasta $30 \%$ menor del legal establecido en origen. ${ }^{77}$ Desde una perspectiva técnica, se opta por la fórmula del resello frente a la refundición por motivos presupuestarios, técnicos y temporales. La operación del resello ${ }^{78}$ según expediente del 9 de noviembre de Félix Sagaut, grabador general, estimando 150000000 de reales en circulación, tras quince días de verificación en

\footnotetext{
${ }^{76}$ Informes de los consulados de Santander, Barcelona y Bilbao y el Ayuntamiento de Madrid.

${ }^{77}$ AHC, Diario de Sesiones, Legislatura extraordinaria de 1821, t. I, p. 720.

${ }^{78}$ Antes de poner los cospeles bajo el volante hay que pesarlos, justificarlos, fundir aquellos faltos de peso, cortarlos, recocerlos, arenarlos, acordonarlos y sellarlos.
} 
las casas de moneda y poniendo a disposición los troqueles precisos, se podría concluir en un plazo inferior a cinco meses resellando diariamente 100000 piezas. Para este fin será preciso que además de las casas de Madrid, Sevilla, Segovia y Jubia, debidamente reforzadas tecnológicamente, operen nuevos centros provisionales de acuñación en frío en Barcelona, ${ }^{79}$ Bilbao y un segundo en Sevilla con la que reforzar la demanda potencial de Cádiz. De otro modo, la refundición hubiese hecho necesario doblar la capacidad productiva y los recursos humanos de las casas de moneda para un proceso de ensaye y acuñación de varios años. ${ }^{80}$ Con el objetivo de incentivar la participación de los tenedores en la operación de recogida, se garantiza que tendrán derecho a recibir la misma cantidad de moneda resellada a razón de 1671/2 reales por marco y el aumento nominal sobre el de su valor efectivo en billetes contra la Tesorería. ${ }^{81}$ De esta forma, la junta directiva y las comisiones territoriales ${ }^{82}$ expiden, por una parte, los resguardos competentes pagaderos al portador en las casas de moneda según orden de presentación y, por otra, los billetes de Tesorería general. La emisión de cierto papel moneda, aún de manera limitada a unos 15000000 de reales, levanta encendidas intervenciones en las Cortes. En España no hay bancos de depósito que emitan papel moneda y el descrédito de los vales reales ha llegado al punto en el que es imposible cerrar una simple operación de 4000 reales con 4000000 en papel. ${ }^{83}$ Asimismo, la deuda contra la Hacienda a través de los billetes consignados, en el supuesto de 150000000 de reales de circulación en moneda francesa, ascendería a 15000000 difíciles de gestionar por un departamento de Hacienda que tuvo que suscribir para el ejercicio de 1820 un empréstito exterior de 200000000 para cubrir el desfase presupuestario. Por último, el proyecto de resello se reactiva en las Cortes a finales del mes de diciembre de 1821 por un doble motivo: el escaso nivel de moneda recogida y la solicitud de prorrogar los plazos establecidos por el proyecto. Las letras que cumplían pronto se han negociado en el mercado con más ventaja que las de 90 días y se han divulgado noticias desacreditando la operación de resello y al propio gobierno. Se extiende la idea de que los medios luises que se presentaban, en vez de resellarse, pasarían a la tesorería para volverlos a poner en circulación rehusando finalmente el gobierno a cumplir con la

${ }^{79}$ Véase Sanahuja, “Çeca”, 1997.

${ }^{80}$ AHC, Diario de Sesiones, Legislatura extraordinaria de 1821, t. I, pp. 712-713.

${ }^{81}$ En el caso del medio luis, cuyo valor según tarifa es de once reales, ahora en el cospel resellado aparecerá diez reales y a los tenedores se le extenderá un billete de un real, pudiendo ser endosables y admisibles en pago de derechos y contribuciones.

${ }^{82}$ En donde exista casa de moneda, director, contador, ensayador y tres miembros del ayuntamiento. En las plazas donde no exista establecimiento de acuñación, dos personas nombradas por el ayuntamiento y dos por el gobierno a instancia de la junta directiva.

${ }^{83}$ AHC, Diario de Sesiones, Legislatura extraordinaria de 1821, t. I, p. 754. 
indemnización prometida a los particulares de 10\%, induciendo con esto a la no presentación en las casas nacionales. En este contexto diversas casas de comercio de Madrid comienzan a acaparar a gran escala medios luises comprándolos primero con el 1/1/2 por 100 de pérdida, y subiendo hasta el $81 / 2$ el 27 de diciembre. De esta manera, los medios luises han venido a parar a pocas manos demandando a las Cortes, por parte de grandes comerciantes, la urgente prórroga en la operación, que logran, parcialmente, a principios del mes de enero, ${ }^{84}$ a pesar de la resistencia de amplios sectores del arco parlamentario.

Los resultados del proyecto son escasos porque, en última instancia, acaba por reforzar los fundamentos de la política tradicional que es la causa principal de la extracción de la plata. Sin variación en la relación bimetálica y sin cambios en la ley y el peso de la nueva moneda constitucional, el proyecto del resello nacional actúa paradójicamente a favor de la política monetaria de moneda fuerte ya que no supone alteración metálica alguna en la moneda nacional, sino una devaluación nominal de la francesa, manteniendo, por consiguiente, las tensiones especulativas de flujo de moneda francesa antes de la entrada en vigor de la ley. El proyecto se erige como el primer intento para acabar con la dependencia y la subordinación monetaria respecto de Francia, pero con escaso calado reformista al eludir la necesaria devaluación. La única virtud que le resta es la de abolir la denostada tarifa de 1818 que abría a la circulación interior monedas francesas de difícil identificación y de ínfima calidad. El volumen total de recogida provisional se puede observar en la gráfica 2 .

Además de estas medidas principales, el trienio examina la problemática del circulante de cobre mediante el cierre cautelar de la Casa de la Moneda de Jubia $;{ }^{85}$ avanza en la reorganización de la deuda pendiente de los vales reales convirtiéndolos, bien en deuda consolidada con interés, o en deuda sin interés susceptible de ser amortizada mediante futuras desamortizaciones; abre el debate en torno a la reforma del sistema de pesos y medidas, incomprensiblemente arrinconado como asunto menor en todas las legislaturas, no pasando del simple estudio de la cuestión, y aprueba una ley de minas para estimular la producción peninsular de plata a modo de compensación por la pérdida del flujo ultramarino. ${ }^{86}$

El retorno del absolutismo fernandino en $1823^{87}$ da por zanjada la experiencia monetaria reformista. La política monetaria, aunque ligeramen-

${ }^{84}$ AHC, Diario de Sesiones, Legislatura extraordinaria de 1821, t. II, p. 1497.

${ }^{85}$ Ibid., Legislatura ordinaria de 1821, t. II, pp. 1518, 2178, 2218.

${ }^{86} \mathrm{Ibid}$., Legislatura ordinaria de 1821, t. III, p. 2225.

${ }^{87}$ Tarifa de Tolosa, decretos del 13 de abril y 21 de junio de 1823, véase Pascual, "Moneda", 2004 . 


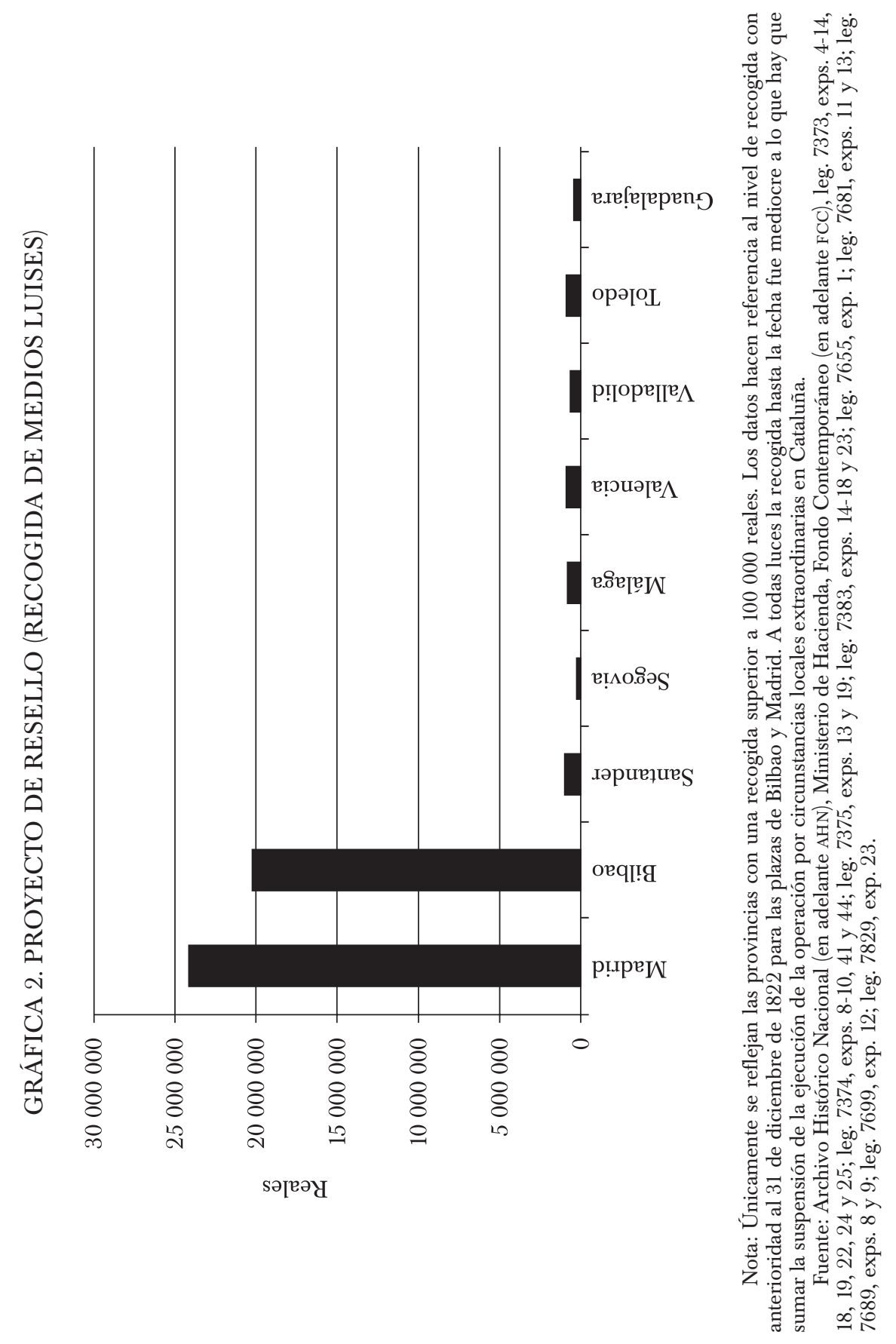


te rectificada, ${ }^{88}$ retrocede al sistema tradicional. El resultado del fracaso reformista se manifiesta en una larga onda depresiva, deflacionista y de crisis del sistema de acuñación, en la que el atesoramiento y exportación del capital nacional ${ }^{89}$ sólo se ven compensados, parcialmente, mediante la suscripción de nuevos empréstitos extranjeros, la persistente entrada masiva de numerario francés ${ }^{90}$ y la legalización progresiva en la circulación interior de numerario portugués, ${ }^{91}$ inglés ${ }^{92}$ y mexicano, ${ }^{93}$ con nuevas tarifas. Sin embargo, el impulso reformista del trienio va a estar presente en todos los proyectos de reforma monetaria que se producen en España en la primera mitad del siglo XIX, pero tendrán que pasar 25 años hasta que finalmente la reforma monetaria de Beltrán de Lis de 1848 oriente la política monetaria en el sentido de la modernización del sistema, empujada por los acontecimientos monetarios internacionales, fluctuaciones en los precios del oro y la plata y la crisis financiera en Francia.

\section{CONCLUSIÓN}

La crisis del antiguo régimen se concluye en lo económico con el hundimiento de las rentas interiores y el colapso de los flujos ultramarinos. El sistema se verá atrapado en el complejo proceso que conlleva el estancamiento de la productividad y la incapacidad de soportar los gastos improductivos de las clases dirigentes y del Estado borbónico. La interrupción del proceso normal de reproducción en forma de espiral conducirá a la reducción progresiva de los limitados excedentes originados en la producción a lo largo de las sucesivas crisis de subsistencia de 1763-1765, 1784-1793 y 1800-1804, condenando a la economía peninsular al estancamiento durante buena parte del primer tercio del siglo XIX. En términos monetarios, la crisis se hace patente en cuanto el sistema bimetálico tradicional pierde su base de aprovisionamiento, esto es, los caudales americanos, resultando cada vez más complicado aplicar una política monetaria tradicional basada en la moneda fuerte. Era en esta coyuntura de doble crisis económica y monetaria, presente en el primer tercio del siglo XIX, el

${ }^{88}$ Decreto del 20 de agosto de 1824.

${ }^{89}$ Vadillo (Reflexiones, 1846) verá en la tarifa de Tolosa como la máxima responsable de las sacas; en cambio, Vázquez (Proyecto, 1847) no la considera un factor determinante. Para conocer con mayor profundidad a este autor, véase Tedde, Proyectos, 2005.

${ }^{90}$ En 1846, según datos aportados por Vadillo (Reflexiones, 1846, p. 52), la moneda francesa vendría a significar 41\% de la oferta monetaria. Para Sardà (Política, 1998, p. 99) ya en 1842 la proporción alcanzaría $50 \%$.

${ }_{91}^{91}$ Decreto del 13 de mayo de 1836.

${ }^{92}$ Decreto del 25 de octubre de 1835.

${ }^{93}$ Decreto del 11 de octubre de 1837. 
momento oportuno de haber procedido a la desarticulación de la política monetaria tradicional, sustituyéndola por una moderna que favoreciese los impulsos incipientes del capitalismo español y procurase un sistema monetario más acorde con las tendencias internacionales. Sin embargo, la crisis del antiguo régimen no vino acompañada de la necesaria transición monetaria, retrasándose ante la interacción de diversos factores.

En primer lugar, hay que tener en cuenta que el sistema tradicional, aun habiendo perdido su base de aprovisionamiento, evitará su colapso a través del proceso de subordinación y dependencia monetaria respecto a Francia. Ello contribuyó a suministrar medios de cambio a una economía sometida a la tensión deflacionaria. Conocida la imposibilidad de incrementar la oferta con valor intrínseco desde las casas de moneda, la escasa demanda de dinero, activada bajo el mínimo impulso industrial y la creciente comercialización del producto agrario, viene a ser cubierta mediante la mayor presencia del numerario francés, evitando así la necesaria transición monetaria que de otra forma hubiese sido inaplazable. De hecho, la reforma monetaria del sistema español sólo comenzará a dar pasos decisivos como consecuencia de la crisis monetaria y financiera francesa de 1847 , que motivará el cierre de los canales de entrada de numerario francés en la península.

En segundo lugar, la política del trienio constitucional supone un cambio muy importante respecto a las viejas concepciones monetarias. El objetivo ya no es tanto el rentista, sino el de garantizar la suficiente liquidez monetaria basada en la plata nacional que alejase de la economía española el fantasma de la deflación. Con la nueva política monetaria articulada en torno a la disminución de los derechos de acuñación, y modernización de las instituciones monetarias, los reformistas persiguen el afloramiento del metal tesaurizado, poner freno a la salida de capitales sin contrapartidas y acabar con la dependencia monetaria respecto a Francia. Sin embargo, en esta amplia reforma monetaria se echa de menos la necesaria devaluación metálica y un ajuste de la relación bimetálica que hubiese permitido despejar definitivamente los perturbadores efectos que la exportación de capitales ejercía sobre el sistema monetario nacional y la economía española. La política monetaria del trienio, aun siendo incapaz de modificar la política de moneda fuerte y sobrevaluación del oro, tiene la virtud, aun de forma imperfecta, de abrir el camino de la transición monetaria, introduciendo un giro modernizador en la política monetaria. No obstante, la nueva política constitucional se enfrenta a dos límites: primero, la corta duración del trienio, que deja sin recorrido las reformas y, segundo, que la propia política reformista, en temas fundamentales, trata los problemas monetarios con criterios del antiguo régimen. 
Por último, en tercer lugar, en cuanto al pensamiento monetario español y los fundamentos de las propuestas de reforma es significativo el notorio desfase respecto a los debates que se desarrollan en las economías avanzadas y la insistencia en conceptos y hábitos tradicionales. En Inglaterra, y en menor medida en Francia, durante la primera mitad del siglo XIX cobran especial relevancia, alentados por las sucesivas crisis de 1825, 1836 y 1839, los debates monetarios y bancarios centrados en controversias modernas. En el caso español, salvo excepciones, no se producen debates monetarios al hilo de las discusiones internacionales, ni mínimos avances hacia el nominalismo. Por el contrario, los debates siguen aferrados a cuestiones tradicionales como es el caso del concepto dinero mercancía. Como se recoge en el Diario de Sesiones de las Cortes, durante la Legislatura de 1821, en el debate de la reforma de las casas de moneda, se insiste en señalar a la moneda como cualquier otro género comerciable, a modo de mercancía cuya confianza en el mercado descansa sobre la solvencia de su ley y su peso. Argumento, por otro lado, reforzado ante la calamitosa experiencia española de los vales reales, cuya amortización efectiva no se producirá hasta la mitad del siglo XIX y que actuará en forma de lastre sobre el mercado privándolo de la confianza necesaria para poder desarrollar el papel moneda. La confianza del mercado, ante la ausencia de un Estado fuerte, de instituciones bancarias y monetarias solventes y un mínimo de nivel de reservas, sigue descansando exclusivamente sobre la moneda fuerte, haciendo muy difícil la superación de viejos obstáculos. De esta forma, se pone de manifiesto la ausencia de debates monetarios acordes a los nuevos tiempos y, a su vez, una actitud refractaria, incluso desde las posiciones reformistas, a la necesaria transición del concepto dinero mercancía en dinero muestra para el desarrollo de las fuerzas del mercado.

\section{FUENTES CONSULTADAS}

\section{Archivos}

AGS Archivo General de Simancas, Valladolid.

AHC Archivo Histórico del Congreso, Madrid.

AHN Archivo Histórico Nacional, Madrid.

\section{Bibliografía}

Amat, Junn De, Balances de las cuentas de la Casa de la Moneda de Cataluña, Palma de Mallorca, Imprenta de Agustín Roca, 1813. 
Anderson, Perry, El Estado absolutista, Madrid, Siglo XXI, 1979.

ANÓNIMO, Breve reseña histórico-crítica de la moneda española y reducción de sus valores a los del sistema métrico vigentes, vol. Resumen de los informes sobre la cuestión monetaria, Madrid, Imprenta Nacional, 1862.

Artola, Miguel, Antiguo régimen y revolución liberal, Barcelona, Ariel, 1991.

BArbier, Jacques y Herbert S. Klein, "Las prioridades de un monarca ilustrado: el gasto público en el reinado de Carlos III", Revista de Historia Económica. Journal of Iberian and Latin American Economic History, Instituto Figueroa de Historia Económica-Universidad Carlos III de Madrid, año 3, núm. 3, 1985, Madrid, pp. 473-495.

Bennasar, Bartolomé, La España del siglo de oro, Barcelona, Crítica, 1983.

Bordo, Michel D. y Peter L. Rousseau, "Legal-Political Factors and the Historical Evolution of the Finance-Growth Link", European Review of Economic History, European Historical Economics Society, vol. 10, núm. 3, diciembre de 2006, pp. 421-444.

Brunhoff, Suzanne de, La oferta de moneda (crítica de un concepto), Buenos Aires, Tiempo Contemporáneo, 1975.

Bustelo, Francisco y Gabriel Tortella-Casares, "Monetary Inflation in Spain, 1800-1970”, Journal European Economic History, Fondazione Istituto Internazionale di Storia Economica F. Datini, año 5, núm. 1, 1976, pp. 141-150.

Canga Argüelles, José, Diccionario de Hacienda, Madrid, Imprenta de Marcelino Calero y Portocarrero, 1833.

CHick, Victoria, La macroeconomía según Keynes. Una revisión de la teoría general, Madrid, Alianza, 1990.

Cipolla, Carlo M., La odisea de la plata española, Barcelona, Crítica, 1999.

Cuenca Esteban, Javier, "Statistics of Spain's Colonial Grade, 1747-1820: New Estimates and Comparisons with Great Britain", Revista de Historia Económica. Journal of Iberian and Latin American Economic History, Instituto Figueroa de Historia Económica, Universidad Carlos III de Madrid, año 26, núm. 3, 2008, pp. 323-354.

Darnis, JeAn-Marie, La monnaie de Paris. Sa création et son histoire du Cosulat et de l'Empire à la Restauration (1795-1826), Levallois, Centre d'Etudes Napoléoniennes, 1988.

Durán, Rafael, "Historia de la Casa de la Moneda y Timbre" en Varios autores, Cien años de historia. Fábrica Nacional de Moneda y Timbre, Madrid, Fábrica Nacional de Moneda y Timbre, 1994.

Ehrenberg, Richard, "Das Zeitalter der Fugger”, Geldkapital und Creditverkehr, Jahrhunderts, núm. 16, 1922, Jena.

Espina Montero, Álvaro, “Oro, plata y mercurio, los nervios de la monarquía española”, Revista de Historia Económica. Journal of Iberian and Latin American Economic History, Instituto Figueroa de Historia Económica-Universidad Carlos III de Madrid, año 19, núm. 3, otoño-invierno de 2001, pp. 507-538.

Fisher, John R., Commercial Relations between Spain and Spanish America in the Era of Free Trade, 1770-1796, Liverpool, Centre for Latin American Studies, 1985. 
FLynn, Dennis O., "El desarrollo del primer capitalismo a pesar de los metales preciosos del Nuevo Mundo: una interpretación anti-Wallerstein de la España imperial", Revista de Historia Económica. Journal of Iberian and Latin American Economic History, Instituto Figueroa de Historia Económica-Universidad Carlos III de Madrid, año 2, núm. 2, marzo-septiembre de 1984, pp. 29-57.

Fontana, Joserh, La quiebra de la monarquía absoluta, 1814-1820 (La crisis del antiguo régimen en España), Barcelona, Ariel, 1971. , La crisis del antiguo régimen 1808-1833, Barcelona, Crítica, 1992.

Francisco Olmos, José MARÍA DE, La moneda de la revolución francesa, Madrid, Castellum, 2000.

GARCÍA-BAQUero, ANTONIO, El comercio colonial en la época del absolutismo ilustrado: problemas y debates, Granada, Universidad de Granada, 2003.

GARCía de PASO, José I., "La estabilización monetaria en Castilla bajo Carlos II", Revista de Historia Económica. Journal of Iberian and Latin American Economic History, Instituto Figueroa de Historia Económica-Universidad Carlos III de Madrid, año 18, núm. 1, invierno de 2000, pp. 49-77.

Gil Novales, Alberto, El trienio liberal, Madrid, Siglo XXI, 1980.

Diccionario biográfico de España (1808-1833). De los orígenes del liberalismo a la reacción absolutista, Madrid, Fundación MAPFre, 2011.

Goig Pansu, Enrique, La moneda catalana de la guerra de la independencia (1808-1814), Barcelona, Sección Numismática del Círculo Filatélico y Numismático, 1974.

Hamilton, EARL J., El tesoro americano y la revolución de los precios en España 1501-1650, Barcelona, Crítica, 2000.

Haro, Dionisio de, La reforma monetaria del trienio constitucional. De la política monetaria ilustrada al reformismo liberal, Madrid, Dykinson, 2006.

Irigoin, María Alejandra, "Finance, Politics and Economics in Buenos Aires, 1820s1860s: The Political Economy of Currency Stabilitation", tesis de doctorado, Escuela de Economía-Universidad de Londres, Londres, 2000.

, "Gresham a caballo: Las raíces monetarias de la fragmentación política de la América española en el siglo XiX” en Carlos Contreras, Cristina Mazzeo y Francisco Quiroz (eds.), Guerra, finanzas y regiones en la historia económica del Perú, Lima, Banco Central de la Reserva del Perú, 2010.

Jaramillo, Julio, Antonio Meisel y Miguel Urrutia, Continuities and Discontinuities in the Fiscal and Monetary Institutions of New Granada, edición de Michael D. Bordo y Ricardo Cortés Conde, Nueva York, Cambridge University Press, 2001.

Kamen, Henry, El siglo de hierro. Cambio social en Europa, 1550-1660, Madrid, Alianza, 1971.

Kriedte, Peter, Feudalismo tardío y capital mercantil, Barcelona, Crítica, 1994.

Levine, Ross, "Finance and growth: theory and evidence" en Philippe Aghion y Steven N. Durlauf (eds.), Handbook of Economic Growth, vol. 1A, Amsterdam, Elsevier B. V., 2005, pp. 865-934. 
Maldonado, Javier, La formación del capitalismo en el marco del Jerez, Madrid, Huerga y Fierro Editores, 1999.

MaluQuer de Motes, Jordi, "El índice de la producción industrial en Cataluña. Una nueva estimación (1817-1935)", Revista de Historia Industrial, Departament d'Història i Institucions Econòmiques-Universitat de Barcelona, núm. 5, 1994, pp. 45-71.

Marichal Salinas, Carlos, "Beneficios y costes fiscales del colonialismo: las remesas americanas a España 1760-1814", Revista de Historia Económica. Journal of Iberian and Latin American Economic History, Instituto Figueroa de Historia EconómicaUniversidad Carlos III de Madrid, año 15, núm. 3, invierno de 1997, pp. 475-505. La bancarrota del virreinato. Nueva España y las finanzas del imperio español, 1780-1810, México, Fondo de Cultura Económica, 1999.

MARX, KARL, Contribución a la crítica de la economía política, Madrid, Alberto Corazón Editor, 1976.

Matamala, JuAn Fernando, "La descentralización de la acuñación en la Nueva España (1810-1821)", Vetas, El Colegio de San Luis, vol. III, núm. 7, 2001, San Luis Potosí.

MATEU y Llopis, Felipe, La moneda española (Breve historia monetaria de España), Barcelona, Ed. Alberto Martín, 1946.

Mitre, Antonio, El monedero de los Andes. Región económica y moneda boliviana en el siglo XIX, La Paz, Hisbol, 1986.

Moral, JOAQUín DEL, Hacienda y sociedad en el trienio constitucional, Madrid, Instituto de Estudios Fiscales, 1975.

MORINEAU, Michel, Incroyables gazettes et métaux précieux. Le retour des trésors américains dáaprés les gazettes hollandaises (XVI-XVIII siècles), Cambridge, Cambridge University Press/Maison des Sciences de l'Homme, 1985.

Murray, Glenn, "Guía de los marcos acuñados y ensayadores de la Casa de la Moneda de Madrid (1615-1868)", Numisma, Sociedad Iberoamericana de Estudios Numismáticos, núm. 233, 1993, España, pp. 295-387.

Nogués Marco, Pilar, "Análisis de la deflación española en la primera mitad del siglo XIX: una comparación internacional”, Revista de Historia Económica. Journal of Iberian and Latin American Economic History, Instituto Figueroa de Historia Económica-Universidad Carlos III de Madrid, año 23, núm. 2, verano de 2005, pp. 371-405.

O’Brien, Denis Patrick, Los economistas clásicos, Madrid, Alianza, 1989.

Paradaltas, Francisco, Tratado de monedas: sistema monetario y proyectos para su reforma, Barcelona, Imprenta Tomás Gaspar, 1847.

Parain, Charles et al., El feudalismo, Madrid, Ayuso, 1972.

Pascual Domènech, Pere, "Moneda e industria. La reforma de 1824 y la acuñación de moneda en Barcelona (1836-1848)", Revista de Historia Industrial, Departament d'Història i Institucions Econòmiques-Universitat de Barcelona, núm. 26, 2004, pp. 57-100. 
Pascual Domènech, Pere y Carles Sudrià Triay, "Quiebra colonial y ajuste monetario en España”, Estudis d'Historia Económica. Societat $i$ Economía a la Prehistoria $i$ Mon Antic, Universidad Palma de Mallorca, núm. 2, 1992, pp. 125-141. "Industrialización, desarrollo financiero y oferta monetaria en Barcelona a mediados del siglo XIX”, Investigaciones de Historia Económica, Asociación Española de Historia Económica, núm. 12, otoño de 2008, pp. 45-77.

Prados de la Escosura, LEANDro, "La pérdida del imperio y sus consecuencias económicas" en LeAndro Prados de la Escosura y SAmuel Amaral (eds.), La independencia americana: consecuencias económicas, Madrid, Alianza, 1993.

Prieto Tejeiro, Enrique, Agricultura y atraso en la España contemporánea, Madrid, Endymión, 1988.

El sistema terrateniente y los límites de la economía española, Madrid, Dykinson, 2008.

Prieto Tejeiro, Enrique y Dionisio de Haro Romero, Las reformas monetarias en la primera mitad del siglo XIX. Una aproximación a la historia monetaria de España desde el trienio constitucional hasta la Ley monetaria de 1848, Madrid, Dykinson, 2004. Historia monetaria de la España contemporánea, Madrid, Dykinson, 2010.

Rousseau, Peter L. y Richard Sylla, "Financial Systems, Economic Growth and Globalization” en Michel D. Bordo, Alan M. Taylor y Jeffrey G. WilliamSON (eds.), Globalization in Historical Perspective, Chicago, University of Chicago Press, 2003, pp. 373-415.

"Financial Revolutions and Economic Growth: Introducing this EEH Symposium”, Explorations in Economic History, núm. 43, 2006, pp. 1-12.

Saint Marc, Michele, Histoire monétaire de la France 1800-1980, París, Presses Universitaires de France, 1983.

SAlat, José, Tratado de monedas labradas en el principado de Cataluña con instrumentos justificativos, Barcelona, Imprenta Antonio Brusi, 1818.

Sanahuja i Anguera, XaVier, "La çeca constitucional de Barcelona (1822-1823)", Acta Numismàtica, Institut d'Estudis Catalans-Societat Catalana d'Estudis Numismàtics, núm. 27, 1997, pp. 111-120.

SARDÀ, JOAN, La política monetaria y las fluctuaciones de la economía española en el siglo XIX, Barcelona, Alta Fulla, 1998.

Tedde de Lorca, Pedro, El Banco de San Carlos (1782-1829), Madrid, Alianza, 1988. Los proyectos monetarios de Vicente Vázquez Queipo en la España de mediados del siglo XIX, Santiago de Compostela, VIII Congreso de la Asociación de Historia Económica, 2005.

"Oro y plata en España: un ensayo de cuantificación (1770-1850). La economía monetaria española y la independencia de América" en ENRIQUE LLOPIS Agelán y Carlos Marichal Salinas (coords.), Latinoamérica y España 18001850. Un crecimiento económico nada excepcional, Madrid, Marcial Pons Historia/Instituto de Investigaciones Dr. José María Luis Mora, 2009. 
Tedde de Lorca, Pedro y Carlos Marichal Salinas, La formación de los bancos centrales en España y América Latina (siglos XIX y XX), vol. 29, Madrid, Banco de España, 1994.

Tepaske, John y Herbert S. Klein, Ingresos y egresos de la Real Hacienda de Nueva España, 2 vols, México, Instituto de Antropología e Historia, 1986-1988 (Colección Científica, 41).

Terrón, Eloy, Sociedad e ideología en los orígenes de la España contemporánea, Barcelona, Península, 1969.

VAdillo, JUAN MANUEl DE, Reflexiones sobre la urgencia de remedio a los graves males que hoy se padecen en España por causa de muchas monedas que circulan en ella, Cádiz, Imprenta de Manuel Bosch, 1846.

VÁZQUez QueIPo, VICENTE, Proyecto de Ley sobre la uniformidad y reforma del sistema métrico y monetario de España, Madrid, Imprenta de J. Martín Alegría, 1847.

VILAR, Pierre, "Los primitivos españoles del pensamiento económico: cuantitativismo y bullonismo" en Pierre Vilar, Crecimiento y desarrollo. Economía e historia. Reflexiones sobre el caso español, Barcelona, Ariel, 1980.

"El tiempo del Quijote" en PIERRE VILAR, Crecimiento y desarrollo. Economía e historia. Reflexiones sobre el caso español, Barcelona, Ariel, 1980.

White, LaWrence H. (ed.), Free Banking, 3 vols., Londres, Edward Elgar, 1992. 